\title{
A formação e o desenvolvimento da profissionalidade do professor de Geografia
}

\section{Education and development of Geography teachers' professionalism}

\author{
Claudivan Sanches Lopes*
}

\begin{abstract}
Resumo: Este artigo trata do processo de apropriação, produção e desenvolvimento dos conhecimentos/ saberes necessários à docência em Geografia. No bojo das pesquisas que têm por escopo a profissionalização dos professores e seu principal corolário - os saberes docentes - pretende-se contribuir, de maneira geral, para o reconhecimento e maior valorização social do trabalho docente e, particularmente, para a melhoria dos processos de formação do professor de Geografia. Para tanto, além de pesquisa bibliográfica que focaliza esse campo de investigação, obtiveram-se dados e informações em observações de aula e entrevistas com cinco professores experientes e especialistas nessa área do currículo escolar que atuam no município de Maringá, PR. Verificou-se que o olhar global dos professores de Geografia sobre seu trabalho e profissão carrega as marcas do campo disciplinar. Os professores percebem que a afirmação do discurso geográfico, seus temas, conceitos e procedimentos no currículo escolar são importantes para o fortalecimento não somente da identidade da disciplina, como da própria profissionalidade. Eles se definem como professores em seu sentido mais genérico, mas buscam reconhecer-se e serem reconhecidos como professores de Geografia. Nesse movimento, apropriam-se de uma determinada tradição geográfica escolar que, alimentada pelo desenvolvimento histórico da ciência de referência e pelo próprio saber produzido e acumulado pela experiência profissional, é avaliada, criticada e recriada continuamente.
\end{abstract}

Palavras-chave: Formação do professor de Geografia. Saberes docentes. Profissionalidade. Ensino de Geografia.

\begin{abstract}
This article discusses the process of appropriation, production and development of the required knowledge for the teaching of Geography. It is based on research about teachers' professionalization and its main issue, which is, teaching knowledge. The article intends to contribute to the acknowledgment and valuing of the teaching profession and, in particular, to the improvement of the processes of Geography teachers' education. In addition to the literature review, information and data were obtained from classroom observations and interviews with five experienced and qualified Geography teachers in Maringá, PR. It was observed that in general Geography teachers have a view of their work and profession common to the professionals of the area. Teachers notice that the geographical discourse, its themes, concepts and procedures are important for the strengthening not only of the identity of the discipline, but also of their own professionalization. Teachers define themselves as teachers in a broad way, but try to be acknowledged as Geography teachers. By doing this, they take as a framework a specific traditional school Geography, which based on the historical development of the referred science and by the produced and accumulated knowledge through their professional experience is evaluated and continuously recreated.
\end{abstract}

Keywords: Geography teacher education. Teaching knowledge. Professionalism. Geography Teaching.

\footnotetext{
* Prof. ${ }^{\circ}$ Dr. ${ }^{\circ}$ do Departamento de Geografia da Universidade Estadual de Maringá. E-mail: cslopes@uem.br

${ }^{*}$ Professor at the Geography Department at the State University of Maringá. E-mail: cslopes@uem.br
} 


\section{Introdução}

A formação de professores e os processos de aquisição dos saberes para o exercício da docência e sua profissionalização são questões atuais que se colocam, em todas as áreas, como elementos fundamentais para a melhoria da qualidade do ensino na escola básica. No campo da Geografia particularmente, observamos, nos últimos anos, um renovado interesse pelo ensino e pela formação do professor dessa disciplina. Trata-se de um movimento que, de diferentes perspectivas, tem contribuído para um incremento quantitativo e qualitativo desse campo de pesquisa. Mesmo que implicitamente, a questão que se refere aos processos de construção e delimitação/explicitação dos saberes ou conhecimentos necessários ao exercício mais eficaz da docência e de consolidação da identidade profissional desse professor é frequente (PONTUSCHKA, 1996; 2001; VESENTINI, 2004; CALLAI, 2001; CAVALCANTI, 2002; 2006). Entendemos, portanto, que estamos diante de um tema promissor e com horizontes cada vez mais ampliados.

São, todavia, significativas as pesquisas que apontam, repetidamente, que, por um lado, os alunos da Educação Básica mostram-se desinteressados pelos conteúdos trabalhados pela Geografia escolar, tendo dificuldades em perceber a importância do conhecimento geográfico em seu dia a dia e, por outro, que os professores enfrentam um mal-estar profissional que tem levado alguns a renunciarem/perderem ao/o papel de "protagonistas da aula", ao desestímulo e, em situações extremas como em outros campos disciplinares, a processos de exaustão e abandono da profissão. Mostram que, em diversas circunstâncias, a atividade docente em Geografia tem sido cativa de práticas não reflexivas e estereotipadas, distantes e, por isso mesmo, incapazes de responder à realidade (PONTUSCHKA, 2000; KATUTA, 2004; KAERCHER, 2006; PEREIRA, 1996; VESENTINI, 1994; CAVALCANTI, 2002; 2004).

Embora existam novos caminhos para se trilhar e se vislumbrem alternativas teóricas e práticas relevantes, não são poucos os obstáculos (novos e velhos) que devem ser superados. Existem questões com raízes fincadas nos processos que, historicamente, têm orientado a formação do professor de Geografia na cultura dessa disciplina no universo escolar e que, é claro, estão aninhadas nas questões estruturais de ordem socioeconômica de nosso país, que, de maneira geral, condicionam a educação escolar.

Os impactos de uma economia cada vez mais globalizada em nosso cotidiano, a intensificação das relações no espaço geográfico internacional e os conflitos dela advindos, a gravidade da questão ambiental no Brasil e em todo o planeta, apenas para citar alguns exemplos, são temas que evidenciam a importância do ensino de Geografia para a compreensão do mundo atual. O conhecimento geográfico permite, de fato, uma leitura dinâmica do mundo e fornece, reiteramos aqui, instrumentos para nele agir. Como explicar, então, o desinteresse do aluno em aprender e o desânimo do professor em ensinar o conhecimento geográfico revelados por algumas pesquisas?

Vale ressaltar que não queremos afirmar a inexistência de experiências pedagógicas significativas nessa área. As indagações, neste momento, visam problematizar o relativo insucesso de docentes - relatado por algumas pesquisas que trabalham com a Geografia na Educação Básica - em provo- 
car o interesse dos alunos por suas aulas e, ao mesmo tempo, alcançar certa satisfação profissional. Aliás, já em meados do século XX, Pierre Monbeig (1957) observava a diferença existente entre a Geografia ensinada com frequência pelos professores nas escolas daquela que desejariam ensinar. $\mathrm{Ou}$ seja, não estamos diante de um fato novo e, talvez, a presença de certa “insatisfação” em qualquer projeto de desenvolvimento profissional possa ser benéfica. Visto que se trata de uma questão complexa, a resposta para essa pergunta não pode ser dada sem uma árdua exegese, que busque compreender sua historicidade, ou seja, os novos cenários sociais vividos por todos e, particularmente, pelo professor de Geografia em sua ação pedagógica.

Podemos afirmar, portanto, que, como em outros campos disciplinares, os resultados das pesquisas apontam para a complexificação da atividade docente e que, deste modo, o exercício profissional do professor de Geografia requer uma formação permanente, na qual devem estar integrados (que é muito distinto da ideia de soma) diferentes tipos de conhecimentos oriundos de diversas fontes, inclusive de sua experiência profissional. Gradativamente, como assinala Pontuschka (2001, p. 129), os professores foram adquirindo “[...] consciência da importância de teorizar a própria prática”.

As pesquisas que focalizam os saberes docentes representam, seguramente, uma das frentes em que se procuram soluções para os problemas que afetam a formação e a prática profissional dos professores no Brasil e em diversas partes do mundo. A perspectiva mais estimulante, de nosso ponto de vista pessoal, é a possibilidade de compreender mais profundamente e explicitar, no presente momento histórico, a natureza e a especificidade dos saberes profissionais do professor. Como ressalta Roldão (2007), o conheci- mento profissional específico do professor, mediante o qual poderia mais facilmente ser reconhecido socialmente, se constitui no "elo mais fraco da profissão”. Crê-se, deste ângulo de visão, que tal empreendimento possa contribuir com o processo de construção da profissionalidade docente e seu desenvolvimento profissional.

A perspectiva aqui defendida e que buscaremos desenvolver corrobora a ideia de que, paralelamente à busca de conhecimentos para o ensino externamente à profissão, é fundamental identificar os conhecimentos produzidos no ensino, ou seja, os conhecimentos produzidos pelos professores em seu contexto sempre complexo de trabalho. Os ventos que sopram da academia sempre são bem-vindos, entretanto estes não são os únicos "motores” que podem fazer mover e desenvolver a profissão. A força da profissão deve brotar, fundamentalmente, do seu interior, pelo estabelecimento de uma comunidade profissional consciente de seu papel no ensino.

\section{A constituição dos saberes da docência como campo de pesquisa: emergência, conceitos e propósitos}

De acordo com Lüdke (2001), foram Tardif, Lessard e Lahaye que, por meio do artigo: Os professores face ao saber: esboço de uma problemática do saber docente, de 1991, apresentaram o conceito de saberes $d a$ docência à comunidadecientífica educacional brasileira. Trata-se de um conceito que encontrou, não sem críticas e refutações, um campo fértil nos programas de pesquisas no Brasil. Estamos, sem dúvida, diante de um tema de expressão internacional e sobre o qual se pode observar um crescente interesse (SHULMAN, 2005a; 2005b; NÓVOA, 1992; 
1995; 2000; TARDIF, 2006; GAUTHIER et al., 1998; GARCIA, 1992; PIMENTA, 1999; GERALDI; FIORENTINI; PEREIRA, 2003; MONTEIRO, 2002; 2003; BORGES, 2004; PACHECO, 1995; MONTERO, 2005).

Na esteira do movimento de profissionalização do ensino ${ }^{1}$, a preocupação com os saberes da docência, questão considerada fundamental para a concretização deste projeto, alcançou prestígio e multiplicaramse, consideravelmente, as pesquisas. Para Nóvoa (1998, p. 31):

Os estudos produzidos pelos autores que trabalham nesta tradição intelectual sublinham a importância de investir a pessoa do professor e de dar um estatuto ao saber emergente da sua experiência profissional, fazendo com que os professores se apropriem dos saberes de que são portadores e os trabalhem do ponto de vista teórico e conceptual. Os professores não são apenas consumidores, mas também produtores de saber. Os professores não são apenas executores, mas são também criadores de instrumentos pedagógicos. Os professores não são apenas técnicos, mas são também profissionais críticos e reflexivos.

O exame da literatura nacional e internacional sobre o tema conduz, frequente

\footnotetext{
${ }^{1} \mathrm{O}$ movimento de profissionalização do ensino - ou o movimento de profissionalização da atividade laboral que os professores realizam nas suas aulas no âmbito institucionalizado da escola - conduziu, nos anos 1990 (na América do Norte, Europa e América Latina), a importantes reformas na formação de professores e inclusive no Brasil. Em nosso país, segundo Laranjeira et al. (1999), as reformas colocaram em evidência a questão dos saberes e das competências nos processos formativos dos professores. Nelas, o professor é encarado como um profissional crítico reflexivo, estando no centro sua atuação profissional. Quando, neste estudo, falamos de ensino, estamos nos referindo à atividade profissional que professores e professoras realizam nas suas aulas no âmbito institucionalizado da escola.
}

e retrospectivamente, ao conceito de "profissional reflexivo", cuja matriz teórica pode ser encontrada na obra de Donald Schön (1992). A “prática profissional reflexiva”, desenvolvida por esse autor e aplicada ao trabalho do professor, é uma referência basal na constituição e no desenvolvimento dessa concepção de pesquisa que busca uma nova compreensão da atividade docente.

Trata-se, como aponta Garcia (1992), de um conceito extremamente utilizado nas pesquisas preocupadas como as novas tendências da formação de professores. “A popularidade é tão grande que se torna difícil encontrar referências escritas sobre propostas de formação de professores que, de algum modo, não incluam este conceito como elemento estruturador” (p. 59). Como explicar tamanha repercussão nos meios educacionais? Na opinião de Garcia (1992, p. 60),

Este autor propôs o conceito de reflexão-na-acção, definindo-o como o processo mediante o qual os profissionais (os práticos), nomeadamente os professores, aprendem a partir da análise e interpretação da sua própria actividade. A importância da contribuição de Schön consiste no facto de ele destacar uma característica fundamental do ensino: é uma profissão em que a própria prática conduz necessariamente à criação de um conhecimento específico e ligado à acção, que só pode ser adquirido através do contacto com a prática, pois, trata-se de um conhecimento tácito, pessoal e não sistemático.

Dos desdobramentos e análises críticas das ideias desenvolvidas por Schön e outros autores mais intimamente ligados às questões educacionais, vieram à luz pesquisas e estudos que atribuem ao professor um "novo papel" no interior do processo educativo, mais central e no qual ele é produtor de saberes profissionais. São emblemáticos, 
neste sentido, o título e o conteúdo do artigo Consciência e acção sobre a prática como libertação profissional dos professores, de J. Gimeno Sacristán (1995, p. 78), do qual extraímos o trecho a seguir:

A possibilidade da teoria fecundar a prática é limitada. Pelo contrário, é necessário incentivar a aquisição de uma consciência progressiva sobre a prática, sem desvalorizar a importância dos contributos teóricos. Neste sentido, a consciência sobre a prática surge com a ideia-força condutora da formação inicial e permanente dos professores. Esta afirmação não pretende corroborar o sentimento, muito corrente no seio dos professores, de que a teoria é irrelevante. Trata-se, apenas, de recusar uma linearidade (unívoca) entre o conhecimento teórico e a acção prática.

A superação de práticas rotineiras e não reflexivas e a tomada de consciência dos professores a respeito dos saberes revelados na prática são instrumentos importantes para uma progressiva libertação dos professores como grupo profissional, bastião do desenvolvimento de sua profissionalidade e de maior qualidade do ensino. O que se deseja, nessa perspectiva, é favorecer a "libertação" do espírito reflexivo e criativo do professor, considerando-o protagonista e investigador de suas próprias práticas.

A convicção de que os professores produzem saberes no contexto de sua prática profissional é condição para romper definitivamente com paradigmas de formação baseados na racionalidade técnica, nos quais concepção e execução são momentos separados e hierarquizados entre si. Segundo Contreras (2002, p. 90), “a ideia básica do modelo de racionalidade técnica é que a prática profissional consiste na solução instrumental de problemas mediante a aplicação de um conhecimento teórico e técnico, previamente disponível, que procede da pesquisa científica”. Entretanto a pesquisa e a análise da prática cotidiana profissional dos professores têm mostrado que esse modelo de orientação tecnicista, legado do positivismo no campo das ciências sociais, não resiste ao presente momento histórico. Ou seja, o pressuposto de que a ciência pode produzir conhecimentos para guiar, com segurança, a ação profissional dos professores na consecução de sua tarefa tem-se mostrado parcial, porque ignora, entre outros aspectos, a complexidade e a singularidade dada pelo contexto de todo processo educativo. É brilhante, neste sentido, a metáfora com que Jackson (2001, p. 197) caracteriza e descreve o ofício dos professores em sala de aula: estes, afirma o autor, "sabem, ou chegam a saber, que o transcurso do progresso educativo se parece mais com o vôo de uma borboleta que com a trajetória de uma bala”.

Compreendemos, dessa forma, que as teorias do saber docente têm como um de seus axiomas a negação categórica de modelos tecnocráticos orientarem a formação e a prática profissional docente. Ou, como assinala Monteiro (2001), representa a tentativa de superar a relação linear e mecânica entre o conhecimento técnico-científico e a prática na sala de aula. Foram, continua a autora, “[...] os limites e as insuficiências dessa concepção [que] levaram à busca de novos instrumentos teóricos que fossem capazes de dar conta da complexidade dos fenômenos e ações que se desenvolvem durante atividades práticas”. Assim, “[...] no bojo desses estudos, foi criada a categoria saber docente que busca dar conta da complexidade e especificidade do saber constituído no (e para o) exercício da atividade docente e da profissão [...]” (p. 130, grifo da autora). Destarte, o professor deixa de ser visto como simples consumidor do conhecimento gerado pela investigação científica. 
A preocupação com os saberes docentes se consubstanciou em novos modelos de pesquisa, que passaram a investigar as práticas dos professores de modo a captar os saberes a elas subjacentes e que, por sua própria natureza, não são facilmente explicitados. Na contramão das pesquisas do tipo processo-produto $^{2}$, que tentam correlacionar os comportamentos do professor ao desempenho dos alunos, colocou-se em evidência os processos relacionados ao pensamento $e$ conhecimentos de professores. Era necessário, nessa perspectiva, lapidar a "experiência bruta” (GAGE, apud CONTRERAS, 2002, p. 95) dos professores (colaborativamente com os mesmos) por meio de processos reflexivos e de pesquisa, pelos quais, metodologicamente, a finalidade é, como bem defende Goodson (2000), “dar voz aos professores”. Para Montero (2005, p. 153, grifo da autora),

O enorme desenvolvimento deste paradigma nos últimos 20 anos significou uma viragem decisiva para entrar no mundo interno dos professores e professoras mediante estratégias de indagação preferencialmente qualitativas e enfoques interpretativos, dando lugar a um tipo de conhecimento mais fiel à complexidade, singularidade, incerteza e conflito de valores que caracterizam a prática profissional do ensino.

2 O programa "processo-produto", como explicam Borges e Tardif (2001, p. 63), “[...] tem por objetivo, de maneira geral, analisar os efeitos das ações dos docentes, ou das performances destes durante o ensino, sobre a aprendizagem dos alunos. Como base na análise das variáveis implicadas no processo, procurava estabelecer uma correlação entre as diferentes performances no ensino, "os processos", e as diferenças de aprendizagem dos alunos, "os produtos". [...] O central dessa abordagem é o comportamento eficaz do professor e a eficiência do ensino, medidos por meio de testes estandardizados do rendimento dos alunos.
O rompimento paradigmático que se operou abriu a possibilidade de superar a pesquisa sobre conhecimentos para o ensino, forjados, com frequência, em circunstâncias especiais e muito distantes da prática cotidiana dos professores, para a investigação dos conhecimentos produzidos no ensino pelos próprios professores. Neste ângulo de visão, a pesquisa educacional continua sua procura por conhecimentos científicos possíveis de serem socializados e postos como fundamentos à prática do professor, mas reconhece que “[...] aplicar essa base científica à efervescência da interação em sala de aula ainda é principalmente uma questão de arte" (GAGE, apud GAUTHIER et al., 1998 p. 95). Certamente que, como afirma Montero (2005, p. 154) “[...] continuam a ser os investigadores os principais responsáveis pela obtenção de conhecimento; o ponto de inflexão verifica-se no diálogo com o saber dos professores".

Com efeito, os desdobramentos dessa teoria permitiram vislumbrar, gradativamente, uma "nova profissionalidade docente", uma "nova cultura profissional”, na qual se torna evidente que, como sintetiza Nóvoa (1992, p. 25), “a formação não se constrói por acumulação (de cursos, de conhecimentos ou técnicas), mas sim através de um trabalho de reflexividade crítica sobre as práticas e de (re)construção permanente de uma identidade pessoal”. Procurou-se elevar o status dos saberes produzidos pelos professores no contexto de sua prática, sem, contudo, restringir o conhecimento profissional docente a esse tipo de saber ou conhecimento. 
As teorias do saber docente, algumas contribuições: Lee S. Shulman, Clermont Gauthier e colaboradores e Maurice Tardif

Lee S. Shulman é um dos pioneiros nas pesquisas sobre o saber docente ou conhecimento de base (knowledge base) para o ensino, e goza de prestígio intelectual tanto em seu país, os Estados Unidos, como em outras partes do mundo. No bojo do movimento pela profissionalização da docência, o programa de pesquisas desenvolvido pelo autor e sua equipe, Desenvolvimento do Conhecimento no Ensino (Knowledge Growth in Teaching), durante a década de 1980 nos Estados Unidos, influenciou as pesquisas sobre a formação de professores, o ensino e as políticas públicas que orientaram, na década subsequente, as reformas nos programas e nos currículos de formação de professores em diversas partes do mundo. Segundo Bolívar (2005. p. 2, grifo do autor):

Elprograma pretendía desarrollar un marco teórico que permitiera explicar y describir los componentes del "conocimiento base” de la enseñanza; por lo que estaba interesado en investigar el desarrollo de conocimiento profesional tanto en la formación del profesorado como en la práctica profesional $\mathrm{y}$, especialmente, cómo los profesores transforman el contenido en representaciones didácticas que utilizan en enseñanza.

Ao longo desse extenso programa de pesquisa, Shulman ${ }^{3}$ e seus colaboradores identificaram o missing paradigm (o

\footnotetext{
${ }^{3} \mathrm{O}$ autor publicou os resultados dessas pesquisas nos Estados Unidos, originalmente em artigos, de 1986 e 1987. Aqui, utilizamos versões desses mesmos artigos traduzidos para o espanhol (SHULMAN, 2005a; SHULMAN, 2005b.).
}

paradigma esquecido), que se refere à forma como os professores transformam em ensino os conteúdos específicos que dominam. Enfatizando o domínio dos conteúdos pelo professor para ensinar, o próprio autor explica que estava interessado em compreender “[...] la manera en que determinados tipos de conocimientos de la materia y estrategias didácticas interactuaban en la mente de los profesores” (2005b, p. 7).

Para o autor, o "esquecimento" da especificidade da matéria ensinada levou as pesquisas a se preocuparem com os aspectos metodológicos e comportamentais relacionados [de maneira generalizada] ao ensino e não com o conteúdo a ser ensinado. Ele procura mostrar que não é possível separar o que se ensina - a matéria ou o conteúdo - de como ensinar - $o$ aspecto metodológico. Nessa perspectiva, embora o corpus de conhecimento que o profissional que aqui poderíamos chamar de um bom professor deve possuir seja constituído de saberes mais gerais e comuns aos professores de diversas áreas do conhecimento, existem particularidades que só podem ser bem compreendidas "do lado de dentro" de cada disciplina.

O professor, segundo Shulman (2005b, p. 12):

Debe compreender las estructuras de la materia enseñada, los principios de la organización conceptual, como también los principios de indagación que ayudan a responder dos tipos de preguntas en cada ámbito del saber: cuáles son, en este ámbito del saber, las ideas y las destrezas importantes? Y de qué manera quienes generan conocimientos en esta área incorporan las nuevas ideas y descatan las defectuosas? Esto es, cuáles son las reglas y los procedimientos de un buen saber académico y de la investigación? 
Podemos observar que, para o autor, as especificidades dentro de cada área são importantes para detectar e analisar necessidades de formação e aperfeiçoamento do professorado ou, no dizer de Sacristán (2000, p. 185), são importantes “[...] para filtrar e enriquecer suas perspectivas epistemológicas”. Essas análises potencializam as pesquisas que, como esta, privilegiam uma área específica do currículo escolar.

Shulman (2005a; 2005b) critica as pesquisas do tipo processo-produto, sobre as quais já fizemos referência, e propõe a instalação de pesquisas que possam contribuir para constituição de uma base de conhecimentos para o ensino, deslocando o foco de atenção, da busca de um padrão eficaz de comportamento docente (como devem agir os professores?), para a busca dos conhecimentos subjacentes à ação dos professores no contexto de sua prática (o que, de fato, sabem os docentes sobre os conteúdos que ensinam?). Para Shulman (2005b), os conhecimentos necessários à docência - seus conhecimentos de base - são os seguintes:

- Conhecimento do conteúdo a ser ensinado: refere-se ao conhecimento da disciplina na qual o professor é um especialista (Geografia, História, Matemática, etc.).

- Conhecimento pedagógico geral: refere-se, especialmente, àqueles princípios e estratégias gerais de manejo e organização da aula que transcendem o âmbito da disciplina que o professor ministra.

- Conhecimento do currículo: trata-se de um especial domínio dos materiais e dos programas que servem como "ferramentas para o ofício” do docente.
- Conhecimento pedagógico do conteú$d o^{4}$ : trata-se do especial amálgama entre matéria e pedagogia que constitui uma esfera exclusiva dos professores, sua forma própria e especial de compreensão profissional.

- Conhecimento dos alunos e de suas características.

- Conhecimento dos contextos educativos: abarca desde o funcionamento do grupo ou da aula, a gestão e o financiamento das unidades escolares, até o caráter das comunidades e das culturas.

- Conhecimento dos objetivos, das finalidades e dos valores educativos e de seus fundamentos filosóficos e históricos.

Para o autor, o Conhecimento Pedagógico do Conteúdo (CPC) é possuidor de um valor particular, porque identifica os corpos de conhecimentos distintivos para o ensino. É essa categoria que permite, com maior probabilidade, distinguir o conhecimento do especialista da matéria do pedagogo. O CPC “[...] representa la mezcla entre materia y didáctica por la que se llega a una comprensión de cómo determinados temas e problemas se organizan, se representan $\mathrm{y}$ se adaptan a los diversos intereses $\mathrm{y}$ capacidades de los alumnos, y se exponen para su enseñanza” (SHULMAN, 2005b, p. 11). Deste modo,

[...] la clave para distinguir el conocimiento base para la enseñanza está en la intersección de la materia y la

\footnotetext{
${ }^{4}$ Essa categoria - em inglês, Pedagogical Content Knowledge - aparece na literatura especializada traduzida também por "conhecimento didático do conteúdo” (BOLÍlVAR, 2005; GARCIA, 1999; MONTERO, 2005), “conhecimento dos conteúdos pedagogizados” (MONTEIRO, 2002a; 2002b; 2003), entre outras.
} 
didáctica, en la capacidad de un docente para transformar su conocimiento de la materia en formas que sean didácticamente impactantes y aun así adaptables a la variedad que presentan sus alumnos en cuanto a habilidades y bagajes.

O CPC tem despertado o interesse de diversos pesquisadores no mundo todo, de maneira especial pela potencialidade dessa categoria para a análise dos processos de formação inicial e continuada de professores nas diversas áreas do conhecimento (MONTEIRO, 2002a; 2002b; 2003; GESS-NEWSOME; LEDERMAN， 1999; GUDMUNDSDÓTTIR; SHULMAN, 2005; MONTERO, 2005). Trata-se de uma categoria de conhecimento docente que, dotada de valor heurístico, permite analisar os processos de formação inicial e continuada de professores de maneira mais pertinente e, neste sentido, tem impulsionado as pesquisas que focalizam os saberes docentes.

Clermont Gauthier et al. (1998, p. 2037), analisando o trabalho de professores e os processos de profissionalização em relação aos saberes de que são portadores, identificam três categorias relacionadas à profissão: “ofício sem saberes”, "saberes sem ofício” e "ofícios feito de saberes”. O seu estudo, segundo Nunes (2001, p. 33), “[...] tem como ponto de apoio as premissas de que, assim como a atividade docente não tem conseguido revelar os seus saberes, as ciências da educação acabam por produzir outros saberes que não condizem com a prática”.

Segundo Gauthier et al. (1998), a caracterização do fazer do professor como “ofício sem saberes” domina um longo período histórico e remonta à institucionalização da educação escolar no século XVIII. Está centrada em ideias preconcebidas de que, para ser um bom professor, basta possuir conhecimento do conteúdo, talento, bom senso, seguir a intuição, ter experiência ou cultura, etc. Ser professor, nessa perspectiva, é ser portador de uma vocação ou missão. A profissionalidade docente, “vazia” de conteúdos mais objetivos e específicos, era conquistada misteriosamente e, por isso, impossível de ser identificada de maneira mais objetiva: o ser professor não era definido pela posse de um saber próprio ou específico, mas por uma inclinação inata.

Inversamente, a situação de "saberes sem ofício” se caracteriza pela formalização de saberes muito distanciados da prática real dos professores. Reduz-se de tal modo a sua complexidade que eles não mais encontram correspondente na realidade. Afirmam os autores: "se tínhamos, no primeiro caso, um ofício sem saberes pedagógicos específicos, no segundo, reduzimo-lo a saberes que provocam o esvaziamento do contexto concreto de exercício do ensino” (GAUTHIER et al., 1998, p. 25).

Os desafios da profissionalização exigem, de acordo com os autores, a superação das duas situações apresentadas. Embora se reconheça que tais enunciados expressam realidades presentes na atividade docente, eles impedem, “[...] de forma perversa, a manifestação de saberes profissionais específicos, porque não relacionam a competência à posse de um saber próprio ao ensino" (GAUTHIER et al., 1998, p. 28). De acordo com Gauthier et al. (1998), os saberes mobilizados pelos professores em sua prática são os seguintes:

- Saberes disciplinares: referentes à matéria a ser ensinada;

- Saberes curriculares: referentes aos programas de ensino;

- Saberes das ciências da educação: referentes a um saber profissional específico que não está diretamente relacionado com a ação pedagógica; 
- Saberes da tradição pedagógica: referentes ao saber dar aulas;

- Saberes experienciais: referentes à jurisprudência particular adquirida no exercício do trabalho;

- Saberes da ação pedagógica: referentes ao saber experiencial dos professores a partir do momento em que se torna público e que é testado por meio de pesquisas realizadas em sala de aula.

Os autores sublinham que o último saber - o saber da ação pedagógica - é o tipo menos desenvolvido no reservatório de saberes do professor e que, paradoxalmente, é o saber mais necessário à profissionalização do ensino. Afirmam, deste modo, que

Não pode haver profissionalização do ensino enquanto esse tipo de saber não for mais explicitado, visto que os saberes da ação pedagógica constituem um dos fundamentos da identidade profissional do professor. De fato, na ausência de um saber da ação pedagógica válido, o professor, para fundamentar seus gestos, continuará recorrendo à experiência, à tradição, ao bom senso, em suma, continuará usando saberes que não somente podem comportar limitações importantes, mas também não o distinguem em nada, ou quase nada, do cidadão comum (GAUTHIER et al., 1998, p. 34).

As pesquisas de Maurice Tardif (2006) em busca dos saberes que servem de base ao ofício de professor são guiadas, como explica o autor, pela tentativa de superar, ao mesmo tempo, o que denomina de "mentalismo" e "sociologismo". O primeiro porque "tende a reduzir o conhecimento, e até a própria realidade, em algumas de suas formas radicais, a representações mentais cuja sede é a atividade do pensamento individual” (p. 12), e o segundo
[...] porque tende a eliminar totalmente a contribuição dos atores na construção concreta do saber, tratando-o como uma produção social em si mesmo e por si mesmo, produção essa independente dos contextos de trabalho dos professores e subordinada, antes de mais nada, a mecanismos sociais, a forças sociais quase sempre exteriores à escola, tais como as ideologias pedagógicas, as lutas profissionais, a imposição e a inculcação da cultura dominante, a reprodução da ordem simbólica, etc. (p. 14-15).

Para estabelecer uma possível articulação entre os aspectos sociais e individuais do saber dos professores, o autor procura “[...] situar o saber do professor na interface entre o individual e o social, entre o ator e o sistema, a fim de captar a sua natureza social e individual como um todo" (TARDIF, 2006, p. 16) $)^{5}$.

Negando que a relação dos professores com os saberes se restrinja à transmissão de conhecimentos produzidos externamente ao seu ofício, Tardif afirma que os mesmos integram em suas práticas diferentes saberes com os quais mantêm diferentes relações. "Pode-se definir o saber docente como um saber plural, formado pelo amálgama, mais ou menos coerente, de saberes oriundos da formação profissional de saberes disciplinares, curriculares e experienciais" (TARDIF, 2006, p. 36). São saberes, como explica o autor, temporais, plurais,

\footnotetext{
${ }^{5}$ Entendemos, em sintonia com o autor, que ênfases exageradas em um ou outro aspecto da realidade educacional (que pode ser compreendida pelo momento histórico em que foram produzidas) podem obscurecer ou simplificar a complexidade do processo educativo. Todavia é preciso ressaltar a importante contribuição que teorias que têm raízes na Sociologia e na Psicologia prestaram e têm prestado à educação. Não é nosso intuito, portanto, eclipsar essas teorias a favor de uma espécie de "glorificação dos saberes docentes” (DIAS-DA SILVA, 2008, p. 434).
} 
heterogêneos, personalizados e situados, e carregam as marcas do ser humano. Para Tardif (2006), os saberes profissionais do professor podem ser assim elencados:

- Saberes da formação profissional (ciências da educação): conjunto de saberes transmitido pelas instituições de formação de professores (escolas normais ou faculdades de ciências da educação).

- Saberes disciplinares: são aqueles que correspondem aos diversos campos do conhecimento, aos saberes de que dispõe a sociedade, tais como se encontram hoje integrados nas universidades sob a forma de disciplinas, no interior de faculdades e de cursos distintos (por exemplo, Matemática, História, Geografia).

- Saberes curriculares: correspondem aos discursos, objetivos, conteúdos e métodos a partir dos quais a instituição escolar categoriza e apresenta os saberes sociais por ela definidos e selecionados como modelos da cultura erudita e de formação para a cultura erudita. Apresentam-se, concretamente, sob a forma de programas escolares (objetivos, conteúdos, métodos) que os professores devem aprender a aplicar.

- Saberes da experiência: são os saberes específicos dos docentes. São produzidos pelos próprios docentes e baseados em seu trabalho cotidiano e no conhecimento do seu meio.

Os saberes da experiência ou experienciais são produzidos pelos próprios professores no exercício de sua prática em sala de aula e profissão. São saberes organizados na experiência e por ela são validados. Tardif entende que a posse desse tipo de saber ou conjunto de saberes poderia permitir aos professores reivindicar um controle socialmente legítimo da profissão, ou seja, é uma das condições básicas “[...] para a criação de uma nova profissionalidade entre os professores dos níveis primário e secundário” (TARDIF, 2006, p. 54-55).

\section{Sobre pesquisa de campo e os procedimentos metodológicos}

A pesquisa de campo que subsidia esta pesquisa está centrada na investigação dos conhecimentos/saberes acumulados/ mobilizados/produzidos por professores de Geografia que atuam no Ensino Fundamental e Médio, ao longo do processo de construção de sua profissionalidade. Para isso, combinamos a observação in loco das práticas desenvolvidas em sala de aula com a realização de entrevistas semiestruturadas, nas quais os sujeitos da pesquisa puderam explicar/explicitar suas práticas e teorias implícitas. O objetivo é ter acesso aos conhecimentos em que se baseiam para a tomada de decisões no trabalho pedagógico. Optamos, neste contexto, pela realização de pesquisa de cunho qualitativo (LÜDKE; ANDRÉ, 1986; BAUER; GASKELL, 2002; CHIZZOTTI, 2003), na qual buscamos analisar o percurso formativo e a prática pedagógica de cinco professores de Geografia que atuam no Ensino Fundamental e Médio em Maringá, estado do Paraná.

De acordo com os pressupostos orientadores da pesquisa, decidimos pela seleção de docentes que possuíam, no momento da coleta de dados, entre oito e dezesseis anos de experiência efetiva em sala de aula. Professores que, de acordo com a categorização proposta por (HUBERMAN, 2000), já tivessem adquirido uma razoável 
experiência profissional e atingido, há certo tempo, o estágio da estabilidade e diversificação na profissão.

Orientados pela elaboração de "tópicos guias” (BAUER; GASKELL, 2002), realizamos duas sessões de entrevistas individuais com os professores selecionados, intercaladas com a observação in loco de situações em sala de aula durante o ano letivo de 2008. De modo sintético, na primeira sessão de entrevistas, solicitamos aos professores que falassem de seu percurso formativo, passando pela escolha da profissão, pela avaliação da formação inicial recebida, o sentido de ser professor e de ser professor de Geografia, de seus projetos de desenvolvimento profissional. Na segunda sessão de entrevistas, mais intimamente relacionada à especificidade do fazer pedagógico-geográfico desses professores, nossas questões se centraram no processo de transformação do conhecimento geográfico em conhecimento a ser ensinado aos alunos, ou seja, visavam captar os saberes de base do processo de construção da profissionalidade desses professores, compreender seus êxitos, suas dificuldades, seus dilemas. As observações estavam centradas nas maneiras de os professores desenvolverem os conteúdos geográficos ensinados aos alunos, de modo a captar, de acordo com os objetivos desta pesquisa, as especificidades dos saberes dos professores da área de Geografia. O corpus da pesquisa foi constituído, portanto, pela sistematização das observações de sala de aula e, fundamentalmente, pela transcrição das entrevistas realizadas (BAUER; GASKELL, 2002).

Após a leitura e imersão no material coletado nas entrevistas e nas observações das aulas, de acordo com a metodologia de análise de conteúdo (MORAES, 1999; BARDIN, 2007), construímos um conjunto de categorias analíticas de modo a permitirem responder as perguntas formuladas por esta investigação e, ao mesmo tempo, estabelecer diálogo com outros trabalhos preocupados com esta mesma temática.

A análise de conteúdo é uma metodologia de pesquisa que possibilita a leitura e a interpretação do conteúdo de inúmeros documentos e, particularmente, de entrevistas realizadas em profundidade, como as que efetivamos nesta investigação. Como afirma Moraes (1999, p. 10), os dados advindos das entrevistas, “[...] chegam ao investigador em estado bruto, necessitando então ser processados para, dessa maneira, facilitar o trabalho de compreensão, interpretação e inferência a que se aspira na análise de conteúdo”. Como permite a descrição sistemática do conteúdo das mensagens analisadas, ela guia o pesquisador a uma compreensão profunda e refinada das mesmas.

\section{Resultados e discussão}

Podemos depreender da análise desenvolvida que a base de saberes - conhecimentos, compreensões, habilidades, disposições e valores - apropriados, transformados e produzidos pelos professores de Geografia participantes desta investigação no processo de formação e desenvolvimento de sua profissionalidade extrapola, largamente, o domínio específico do campo disciplinar em que são especialistas. E que, analiticamente, além do próprio conhecimento geográfico e de ciências afins, essa base é constituída de conhecimentos pedagógicos gerais sobre os currículos escolares, a psicologia, a sociologia da educação, as políticas educacionais, a filosofia e os fundamentos da educação -, do contexto educativo e das características dos alunos - muito particularmente de suas vivências geográficas -, além daqueles adquiridos na própria 
experiência profissional, com grande relevo para o Conhecimento Pedagógico do Conteúdo (CPC) proposto por Shulman (2005a; 2005b). Referem-se, como afirmam os autores que dão sustentação a este trabalho (SHULMAN, 2005a; 2005b; TARDIF, 2006; GAUTHIER, et al., 1998), a saberes "plurais”, "heterogêneos", "personalizados”, e procedem de fontes diversas. Confirmam, quanto à sua natureza, que estamos diante de saberes que, segundo diferentes denominações, são “compósitos” (ROLDÃO, 2007), “amálgamas” (TARDIF 2006), "mesclas" (SHULMAN, 2005a; 2005b), porque, quando mobilizados na prática, mantêm uma relação de organicidade uns com os outros.

Verificamos que os saberes adquiridos na prática profissional e na colaboração interpares, aqui categorizados como sabedoria prática (SHULMAN, 2005a; 2005b) ou saberes da experiência (GAUTHIER et al., 1998), são os mais destacados e valorizados por nossos colaboradores, sobretudo quando comparados aos saberes adquiridos em outras fontes, como na formação inicial. Para eles, as diversas teorias e técnicas aprendidas no âmbito da universidade e até mesmo aquelas apropriadas em cursos e palestras que compõem a formação continuada não revelaram suficientemente os saberes necessários ao ensino. Não desvalorizam a formação inicial e continuada recebida, mas consideram que estas, de maneira geral, não dão conta ou não satisfazem as questões postas pela realidade, cotidianamente experienciada por esses profissionais.

Deste modo, na análise de sua formação inicial, os professores reclamam, em suma e mais contundentemente, da falta de pedagogia quando cursaram as disciplinas específicas, e da falta de Geografia quando cursaram as disciplinas pedagógicas. A reflexão pedagógica nem sempre considerava a natureza do conhecimento geográfico, a matéria que seria ensinada e, por outro lado, a reflexão proporcionada pelas disciplinas de conhecimentos específicos nem sempre conseguia revelar seu sentido pedagógico, quer dizer, sua importância para a formação de não-geógrafos, para a formação mais geral de crianças e jovens e as estratégias a eles relacionadas. A falta de organicidade entre as diversas disciplinas que compunham o currículo faz com que os professores concluam: eu aprendi realmente aqui, na prática. Assim (na avaliação desses professores), a profissionalidade do professor é construída fundamentalmente na prática (pela análise do contexto), por um processo complexo de estabelecimento de nexos entre esses dois tipos de conhecimentos. Ao empenhar-se nessa tarefa, o professor produz um conhecimento específico que carrega as marcas de sua criatividade e de sua subjetividade. Por intermédio da experiência refletida, o professor armazena uma série de estratégias e maneiras de agir que compõe, dinamicamente, um repertório de saberes que permitem a ele dominar, continuamente, a profissão.

Em nossa interpretação, o processo de vir a ser professor, o domínio da situação docente envolve um trabalho qualificado, que consiste em transformar o conhecimento científico, adquirido nos bancos das universidades e em outras fontes, de modo a torná-lo significativo e assimilável pelos alunos. O que qualifica, destarte, o domínio do conhecimento geográfico do professor desta disciplina e, ao mesmo tempo, o distingue tanto do geógrafo bacharel como do pedagogo é a posse de um conteúdo para ensinar.

É preciso ressaltar que os professores não desconsideram o papel e a importância da formação inicial para o futuro profissional e destacam, positivamente, a experiência que nela tiveram. Em conjunto, todavia, os professores parecerem reivindicar a substituição 
de uma lógica curricular excessivamente disciplinar ou academicista por uma lógica profissional. Os professores que participaram de nossa pesquisa revelam uma queixa comum: a graduação lhes proporcionou dominar os conteúdos a serem ensinados, mas não lhes proporcionou desenvolver ideias claras ou precisas sobre as maneiras de estruturá-los e de torná-los acessíveis a alunos diferenciados e de diferentes níveis de ensino. Como afirma uma das professoras que participaram desta pesquisa:

Na faculdade, aprendemos o conteúdo como alunos, mas pouco aprendemos em como ensinar este conteúdo aos alunos. Em muitos casos, o que fica de modelo a ser ou não seguido é o como nos ensinaram, porém, quando nos deparamos com a nossa sala de aula, o contexto é outro. Então, saber o conteúdo é fundamental para o professor, bem como dominar algumas estratégias do como ensinar. Mas é na experiência prática que aperfeiçoamos estas técnicas e construímos outras.

Assim, os professores que participaram de nossa pesquisa avaliam, com bastante lucidez, que a graduação lhes proporcionou aprender, em níveis variados, por um lado, conhecimentos geográficos e, por outro, métodos, técnicas e teorias gerais de aprendizagem, mas eles não aprenderam suficientemente como ensinar Geografia. Destarte, a falta de organicidade entre as diversas disciplinas que compõem o currículo, notadamente entre as de conhecimentos geográficos e as de conhecimentos pedagógicos, é para eles o calcanhar de Aquiles da formação inicial de professores. Ao privilegiar a lógica acadêmica das disciplinas presentes no currículo, a formação inicial obscureceu ou tornou secundária a lógica da profissionalidade docente em Geografia. Ou seja, a experiência e a função profissional mais específica, vivenciadas pelos professores na sala de aula, foram pouco ou muito pouco discutidas e problematizadas.

Em nossa análise, para além do natural distanciamento entre o processo formativo de qualquer categoria profissional e as atividades mais concretas que compõem sua profissionalidade, a realidade flagrada nesta investigação indica o esgotamento de um modelo de formação e de profissionalidade, insistentemente criticado neste trabalho, que, apoiado na racionalidade técnica, simplifica e reduz as demandas para o exercício profissional dos professores. Ademais, oculta a especificidade e a complexidade de seu ofício e lhes dificulta apropriarem-se coletivamente daqueles saberes que, reconhecidos como seu patrimônio profissional, podem servir aos justos anseios de profissionalização desta categoria.

Deste modo, ao ingressarem na profissão, os professores se viram diante de um "território surpreendentemente desconhecido", que se sentiam desafiados a explorar, mas relativamente despreparados para fazê-lo. O choque com a realidade, amenizado, no caso de duas professoras, pela experiência anterior no primeiro e segundo ciclos do Ensino Fundamental, é uma categoria que exprime muito bem esse sentimento que, como relatam os autores que dão sustentação a este trabalho, frequentemente, é causa de desistência e abandono da profissão.

Constatamos que, no intento de ampliar sua profissionalidade, os professores investiram e investem esforços, sobretudo, na gestão dos conteúdos de ensino e na gestão da classe (GAUTHIER, et al., 1998), duas grandes áreas ou dimensões da competência profissional do professor, as quais, conjuntamente, constituem o núcleo da vida em sala de aula. Representam tarefas que 
correspondem a duas funções pedagógicas fundamentais e inter-relacionadas exercidas pelo professor e que estão no cerne de sua atividade profissional: a de instruir e a de educar.

A gestão da classe, que muito inquieta e angustia os professores que participaram desta pesquisa, está relacionada à constante preocupação em manter a disciplina dos alunos na sala de aula e estabelecer contratos pedagógicos que, sem serem autoritários, proporcionem ao grupo o ambiente considerado mais adequado ao ensino e à aprendizagem; em suma, à capacidade de estabelecer uma boa relação com os alunos. Envolve, portanto, questões de natureza organizacional e interacional. Vimos que os investimentos afetivos e o sentido de comprometimento com os alunos e a comunidade escolar são alavancas para o desenvolvimento profissional dos professores, mas, em um momento em que a sociedade impõe ao professorado novas atribuições e tarefas, vale destacar também a importância da habilidade de enfrentar situações de conflito e violência no ambiente escolar. Situações que, segundo diversas pesquisas e os próprios relatos dos meios de comunicação, estão se intensificando e, se não forem objeto de reflexões coletivas da categoria, podem facilmente converter-se em fator de risco para a saúde física e psicológica dos professores.

A gestão dos conteúdos, que nos propusemos analisar mais detalhadamente neste trabalho, refere-se à tarefa de ensinar com desenvoltura e, de certo modo, fazer valorizar os conteúdos geográficos que ensinam. Em outras palavras, à capacidade de transformar, crítica e criativamente, os diversos temas selecionados pelo currículo para serem ensinados aos alunos de maneira significativa.
Verificamos, neste sentido, que o olhar global dos professores de Geografia sobre seu trabalho e sua profissão carrega as marcas de seu campo disciplinar. Envolvidos na tarefa mais ampla de educar e contribuir para a formação de cidadãos, eles o fazem ou tentam fazê-lo, em grande medida, “do lado de dentro" da disciplina que lecionam. Estas constatações nos possibilitam afirmar que os saberes mobilizados/produzidos pelos professores colaboradores desta investigação em sua prática profissional são tingidos pelas cores e tons do campo disciplinar com o qual trabalham, a Geografia. Eles percebem que a afirmação do discurso geográfico, com seus temas, conceitos e procedimentos no currículo escolar, é um fator importante para o fortalecimento não apenas da identidade da disciplina, como de sua própria profissionalidade. Eles se definem como professores em seu sentido mais genérico, porém se reconhecem e são reconhecidos como professores de Geografia. Pela organização e implementação de práticas e atividades de educação geográfica, eles se apropriam de conceitos, temas, procedimentos e valores que estão em constante evolução, os mobilizam, em diversos níveis de profundidade, e tocam outros campos do currículo escolar, mas sempre expressando especificidades desse campo disciplinar. O professor incorpora, nesse movimento, uma determinada tradição geográfica escolar que, alimentada pelo desenvolvimento histórico da ciência de referência e pelo próprio saber produzido e acumulado pela experiência profissional, é avaliada, criticada e recriada continuamente. Não se trata, evidentemente, de um processo natural e unívoco. Pode comportar avanços e retrocessos.

Ficou evidenciado que cabe ao professor de Geografia, por força mesmo da natureza e função social da instituição escolar, pensar continuamente nas possibilidades 
pedagógicas de sua disciplina no currículo escolar. Mais do que isto e desejavelmente, cabe-lhe pensar de maneira crítica sobre a real contribuição que sua disciplina, seus temas e conteúdos selecionados para comporem os currículos e os programas escolares oferecem para a formação geral dos alunos. No desempenho de seu ofício, os professores se deparam, inevitavelmente, com as diferenças existentes entre uma exposição teórica, típica do ambiente universitário e acadêmico, e uma exposição didáticopedagógica, típica do ambiente escolar da educação básica. Na primeira, seu autor leva em conta o estado do conhecimento, ou seja, sua preocupação primeira diz respeito ao progresso e à evolução de determinado campo da ciência. Na segunda, seu autor deve levar em consideração, também, como afirma Forquin (1992, p. 33) “[...] o estado do conhecente, os estados do ensinado e do ensinante, sua posição respectiva com relação ao saber e a forma institucionalizada da relação que existe entre um e outro, em tal ou qual contexto social”. Não se trata, arremata o autor, citando Verret, "[...] apenas de fazer compreender, mas também de fazer aprender, isto é, de fazer com que o saber se incorpore ao indivíduo sob a forma de esquemas operativos ou de habitus" (p. 33). O que em uma exposição teórica (acadêmica) poderia ser considerado como redundância (repetições, analogias, exemplificações, enfim, recursos perifrásticos, abundantemente observados nas práticas dos professores no universo escolar), em uma exposição didático-pedagógica é uma necessidade, uma característica sui generis da cultura escolar. Enquanto o pesquisador é guiado precipuamente pelo estado da arte de seu campo de conhecimento, seus problemas e desafios, o professor lida com o imperativo de, levando em consideração o estado dos aprendizes e seu contexto, ou seja, o tempo e o espaço em que eles realizam sua tarefa, ser capaz de ensiná-los. É esse "imenso trabalho" - porque complexo e exigente, usando uma expressão de Forquin (1992, p. 32) - que caracteriza a práxis e a profissionalidade docente. $\mathrm{O}$ professor não ensina apenas informações geográficas aos alunos, e sim, essencialmente, uma maneira específica de olhar para o mundo (o olhar geográfico), de compreendê-lo, de "poder agir", visando, numa perspectiva crítica desejável, a uma possível transformação.

Conforme constatamos pela análise dos dados levantados nesta investigação, o processo de reflexão pedagógica que os professores desenvolvem, com o intuito de tornar acessíveis, atraentes e úteis aos alunos os conhecimentos geográficos que desejam ensinar, não ocorre à margem da natureza dos temas e conteúdos selecionados pelo currículo. Desse modo, a categoria de conhecimento docente apresentada por Shulman (2005a; 2005b), o Conhecimento Pedagógico do Conteúdo, que, considerando a especificidade deste trabalho, poderíamos apropriadamente denominar de Conhecimento Pedagógico Geográfico, foi muito importante para atingirmos os objetivos propostos por esta pesquisa. Trata-se de uma ferramenta teórica que nos permite ver e compreender de um ângulo privilegiado a especificidade do ofício docente. No ato docente (neste caso, em Geografia), o conhecimento geográfico, os conhecimentos pedagógicos gerais e os $\mathrm{Co}$ nhecimentos do contexto da ação educativa se mesclam e dão origem ao conhecimento pedagógico geográfico. Ele é, sem dúvida, um sinal evidenciador da compreensão especial dos conteúdos que uma docência de qualidade exige, e revela, concomitantemente, o desenvolvimento da profissionalidade docente. 


\section{Considerações finais}

Conquanto o foco principal da investigação aqui apresentada tenham sido as práticas de sala de aula, sobretudo a análise dos saberes pedagógicos geográficos mobilizados no cotidiano escolar, é preciso considerar o contexto social em que essas práticas estão aninhadas. A prática docente dos professores de Geografia, ou de qualquer outra disciplina, está condicionada a circunstâncias sócio-históricas que, de fato, modelam a prática mais imediata do professor na sala de aula; mas é preciso acrescentar, por outro lado, que restringir sua ação a determinações externas, instaladas no plano macroestrutural, seria um fator de desprofissionalização. Em suma, como afirma Sacristán (1995, p. 74): “O professor é responsável pela modelação da prática, mas esta é a intersecção de diferentes contextos". Notamos que, se, por um lado, tal consciência é "libertadora” porque atribui ao professor um papel destacado no processo educativo -, por outro, ela estabelece certos limites ao "poder da prática” dos professores em sala de aula. Investir na profisissionalidade do professor significa ampliar suas possibilidades de ação e dar-lhe maior autonomia sem supervalorizar o poder da prática mais imediata do professor em sala de aula. Os professores desempenham um papel fundamental no "jogo educativo", contudo não é apenas deles a responsabilidade pelas vitórias nem pelos fracassos nesse campo. Responsabilizá-los, por exemplo, por todas as mazelas da educação é uma maneira sutil e ideológica de desviar o foco daquilo que, de fato, condiciona o trabalho do professor em sala de aula.

A dinâmica de valorização intelectual que aqui se vislumbra não pode ser, portanto, um projeto individual. Seguramente, ela depende de condições estruturais ainda não totalmente existentes; pressupõe que é preciso reconhecer o papel destacado que os professores desempenham no processo educativo, sem acreditar, entretanto, que tudo depende deles. Conceber o ofício docente como trabalho intelectual significa reconhecer as possibilidades que os professores possuem de resolver os complexos problemas pedagógicos por eles enfrentados cotidianamente na sala de aula e tornar significativos os conteúdos que ensinam, sem, contudo, negligenciar a necessária compreensão crítica do contexto social no qual desenvolvem sua ação educativa. Para a construção de uma sociedade mais justa e democrática, é necessário articular, conscientemente, diferentes níveis de ação: a mais imediata (mas não menos complexa) que se desenvolve no interior da sala de aula, a da esfera política das lutas profissionais coletivas em sua devida conexão com interesses das comunidades onde atuam, até as questões maiores em que essas comunidades estão envolvidas. Como investigadores educacionais, assumimos, também nós, como sugere Goodson (1999), o papel de "intelectuais públicos”. Nesta condição, professores e investigadores podem unir-se politicamente em um coro de vozes que, conquanto eventualmente possa conter dissonâncias, levanta-se para defender o valor e a importância do ofício do professor na sociedade. Não se trata de defender, corporativamente, os interesses de uma categoria profissional, e sim de assegurar a todos, democraticamente, direitos sociais já consagrados como bens públicos. A “voz dos professores” e a "voz dos investigadores" firmam-se mutuamente pela luta incessante por uma educação de qualidade. O presente trabalho quis ser um esforço nessa direção.

\section{Referências}

BARDIN, L. Análise de conteúdo. Lisboa: Setenta, 2007. 
BAUER, M. W.; GASKELL, G. Pesquisa qualitativa com texto, imagem e som: um manual prático. 5. ed. Petrópolis: Vozes, 2002.

BOLÍVAR, A. Conocimiento didáctico del contenido e didácticas específicas. Profesorado. Revista de currículum y formación del profesorado, GranadaEspaña, ano 9, n. 2, p. 1-39, 2005. Disponível em: <http:// www.ugr.es/local/recfpro/ rev92art6.pdf $>$. Acesso em: 20 out. 2006.

BORGES, M. C. F. O professor da educação básica e seus saberes profissionais. Araraquara: JM, 2004.

BORGES, C.; TARDIF, M. Os saberes dos docentes e sua formação: apresentação. Educação \& Sociedade, Campinas, SP, ano 22, n. 74, p. 11-26, 2001.

CALLAI, H. C. A Geografia e a escola: muda a geografia? Muda o ensino? Terra Livre, São Paulo, n. 16, p. 133-152, 2001.

CAVALCANTI, L. S. Geografia e práticas de ensino. Goiânia: Alternativa, 2002.

CAVALCANTI, L. S. Bases teórico-metodológicas da Geografia: uma referência para a formação e a prática de ensino. In: CAVALCANTI, L. S. (Org.). Formação de professores: concepções e práticas em Geografia. Goiânia: Vieira, 2006. p. 27-49.

CHIZZOTTI, A. Pesquisa em ciências humanas e sociais. 6. ed. São Paulo: Cortez, 2003.

CONTRERAS, J. A autonomia dos professores. São Paulo: Cortez, 2002.

FORQUIN, J. C. Saberes escolares, imperativos didáticos e dinâmicas sociais. Teoria \& Educação, Porto Alegre, n. 5, p. 28-49, 1992.

GARCIA, C. M. A formação de professores: novas perspectivas baseadas na investigação sobre o pensamento do professor. In: NÓVOA, A. (Coord.). Os professores e a sua formação. Lisboa: Dom Quixote, 1992. p. 51-76.

GARCIA, C. M. Formação de professores para uma mudança educativa. Porto: Porto, 1999.

GAUTHIER, C. et al. Por uma teoria da pedagogia: pesquisas contemporâneas sobre o saber docente. Ijuí, RS: Unijuí, 1998.

GERALDI, C. M.; FIORENTINI, D.; PEREIRA, E. M. (Orgs.). Cartografias do trabalho docente. Campinas: Mercado das Letras, 2003.

GESS-NEWSOME， J.; LEDERMAN, N. G. Examining pedagogical content knowledge: the construct and its implications for science teaching. Dordrecht: Kluwer, 1999.

GOODSON, I. The education researcher as a public intellectual. British Research Journal, London, v. 25, n. 3, p. 277-297, 1999.

GOODSON, I. Dar voz ao professor: as histórias de vida dos professores e o seu desenvolvimento profissional. In: NÓVOA, A. (Org.). Vida de professores. 2. ed. Porto: Porto, 2000. p. 63-78.

GUDMUNDSDÓTTIR, S.; SHULMAN, L. S. Conocimiento didáctico en ciencias sociales. Profesorado. Revista de currículum y formación del profesorado. Granada-España, ano 9, n. 2, p. 1-12, 2005. Disponível em: <http:// www.ugr.es/local/recfpro/ rev92art5.pdf>. Acesso em: 27 jul. 2007.

HUBERMAN, M. O ciclo de vida profissional dos professores. In: NÓVOA, A. (Org.). Vidas de professores. 2. ed. Porto: Porto, 2000. p. 33-61.

JACKSON, Ph. W. La vida en las aulas. 6. ed. Madrid: Morata/Paideia, 2001. 
KAERCHER, N. A. A geografia escolar na prática docente: a utopia e os obstáculos epistemológicos da Geografia crítica. São Paulo: USP/FFLCH, 2004. Tese (Doutorado em Geografia Humana). Disponível em: $<$ www.teses.usp.br>. Acesso em: 20 jan. 2006.

KATUTA, A. M. O ensino da Geografia e as figurações espaciais. In: ROMANOWISKI, J. P.; MARTINS, P. L. O.; JUNQUEIRA, S. R. A. (Orgs.). Conhecimento local e conhecimento universal: práticas sociais, aulas, saberes e políticas. v. 4. Curitiba: Champagnat, 2004. p. 113-130.

LARANJEIRA et al. Referências para a formação de professores. In: BICUDO, M. A.; SILVA JUNIOR, C. (Orgs.). Formação do educador e avaliação institucional. São Paulo: Unesp, 1999. p. 17-50.

LÜDKE, M.; ANDRÉ, M. E. D. A. Pesquisa em educação: abordagens qualitativas. São Paulo: EPU, 1986.

LÜDKE, M. O professor, seu saber e sua pesquisa. Educação e Sociedade. Campinas, SP, Cedes, ano 22, n.74, p.77-96, 2001.

MONBEIG, P. Novos estudos de Geografia humana brasileira. São Paulo: Difusão Européia do Livro, 1957.

MONTEIRO, A. M. F. C. Professores: entre práticas e saberes. Educação e Sociedade, Campinas, Cedes, n. 74, ano 22, p. 121-142, 2001.

MONTEIRO, A. M. F. C. Ensino de história: entre saberes e práticas. Rio de Janeiro: 2002, Tese (Doutorado em Educação) - Pontifícia Universidade Católica do Rio de Janeiro, Rio de Janeiro, 2002a.

MONTEIRO, A. M. A prática de ensino e a produção de saberes na escola. In: CANDAU, V. M. (Org.). Didática, currículo e saberes escolares. 2. ed. Rio de Janeiro: DP\&A, 2002b. p. 129-147.
MONTEIRO, A. M. C. Entre saberes e práticas: a relação de professores com os saberes que ensinam. In: ANPED, REUNIÃO ANUAL. 26., 2003, Poços de Caldas. 2003, Poços de Caldas. Anais eletrônicos... Rio de Janeiro, 2003.

MONTERO, L. A construção do conhecimento profissional docente. Lisboa: Instituto Piaget, 2005.

MORAES, R. Análise de conteúdo. Educação, Porto Alegre, ano 22, n. 37, p. 7-37, 1999.

NÓVOA, A. Formação de professores e profissão docente. In: NÓVOA, A. (Coord.). Os professores e a sua formação. Lisboa: Dom Quixote, 1992. p. 13-33.

NÓVOA, A. O passado e o presente dos professores. In: NÓVIA, A. (Org.). Profissão professor. Porto: Porto, 1995. p. 13-34.

NÓVOA, A. Relação escola-sociedade: “novas respostas para um velho problema”. In: SERBINO, R. V. (Org.). Formação de professores. São Paulo: UNESP, 1998. p.19-39.

NUNES, C. M. F. Saberes docentes e formação de professores: um breve panorama da pesquisa brasileira. Educação \& Sociedade, Campinas, SP, ano 22, n. 74, p. 27-42, 2001.

PACHECO, J. A. Formação de professores: teoria e práxis. Braga: Instituto de Educação e Psicologia - Universidade do Minho, 1995.

PEREIRA, D. Geografia escolar: uma questão de identidade. In: RUFINO, S. M. V. C. (Org.). Ensino de geografia. Cadernos Cedes, Campinas, SP, n. 39, p. 47-56, 1996.

PIMENTA, S. G. Formação de professores: identidade e saberes e saberes da docência. In: PIMENTA, S. G. (Org.). Saberes pedagógicos e atividade docente. São Paulo: Cortez, 1999. p. 15-34. 
PONTUSCHKA, N. N. O perfil do professor e o ensino/aprendizagem da Geografia. Cadernos Cedes: Ensino de geografia. Campinas, SP, n. 39, p. 57-63, 1996.

PONTUSCHKA, N. N. Geografia, representações sociais e escola pública. Terra Livre, São Paulo, n. 15, p. 145-154, 2000.

PONTUSCHKA, N. N. A Geografia: ensino e pesquisa. In: CARLOS, A. F. (Org.). Novos caminhos da Geografia. São Paulo: Contexto. 2001. p. 111-142.

PONTUSCHKA; N. N.; PAGANELLI, T. I.; CACETE, N. H. Para ensinar e aprender Geografia. São Paulo: Cortez, 2007.

ROLDÃO, M. C. Função docente: natureza e construção do conhecimento profissional. Revista Brasileira de Educação. São Paulo, v. 12 n. 34, p. 94-103, 2007.

SACRISTÁN, J. G. Consciência e acção sobre a prática como libertação profissional dos professores. In: NÓVOA, A. (Org.). Profissão professor. Porto: Porto, 1995. p. 63-92.

SACRISTÁN, J. G. O currículo: uma reflexão sobre a prática. 3. ed. Porto Alegre: Artmed, 2000.

SCHÖN, D. A. Formar professores como profissionais reflexivos. In: NÓVOA, A. (Coord.). Os professores e a sua formação. Lisboa: Dom Quixote, 1992, p. 77-91.

SHULMAN, L. S. El saber y entender de la profesión docente. Estúdios Públicos, Santiago-Chile, n. 99, p. 195-224, 2005a.

SHULMAN, L. S. Conocimiento y enseñanza: fundamentos de la nueva reforma. Profesorado. Revista de Currículum y Formación del Profesorado, GranadaEspaña, ano 9, n. 2, p. 1-30, 2005 b. Disponível em: <http://www.ugr.es/local/ recfpro/rev92art1.pdf $>$. Acesso em: 27 maio 2007.
TARDIF, M. et al. Os professores face ao saber: esboço de uma problemática do saber docente. Teoria \& Educação, n. 4, p. 215253, 1991.

TARDIF, M. Saberes profissionais dos professores e conhecimentos universitários. Revista Brasileira de Educação, Rio de Janeiro, n. 13, p. 5-24, jan./fev./mar./abr. 2000.

TARDIF, M. Saberes docentes e formação profissional. 6. ed. Petrópolis: Vozes, 2006.

TARDIF, M.; LESSARD, C. (Orgs.). Ofício de professor: história, perspectivas e desafios internacionais. Petrópolis: Vozes, 2008.

VESENTINI, J. W. Geografia crítica e ensino. In: OLIVEIRA, A. U. (Org.). Para onde vai o ensino de geografia? 4. ed. São Paulo: Contexto, 1994. p. 30-38.

VESENTINI, J. W. Realidades e perspectivas do ensino de geografia no Brasil. In: . (Org.). $O$ ensino de geografia no século XXI. Campinas: Papirus, 2004. p. 219-248.

Enviado em: 30/03/2010

Aceito em: 01/06/2011 